\title{
Intensification of anaerobic digestion efficiency with use of mechanical excess sludge disintegration in the context of increased energy production in wastewater treatment plants
}

\author{
Monika Żubrowska-Sudo1 ${ }^{1}$, Jolanta Podedworna $^{1}$, Agnieszka Bisak $^{1}$, \\ Katarzyna Sytek-Szmeichel ${ }^{1, *}$, Piotr Krawczyk ${ }^{2}$, and Agnieszka Garlicka ${ }^{1}$ \\ ${ }^{1}$ Warsaw University Of Technology, Faculty of Building Services, Hydro and Environmental \\ Engineering, ul. Nowowiejska 20, 00-653 Warsaw, Poland \\ ${ }^{2}$ Warsaw University Of Technology, Faculty of Power and Aeronautical Engineering, \\ ul. Nowowiejska 20, 00-655 Warsaw, Poland
}

\begin{abstract}
The main goal of the study was to evaluate the effects of mechanical sludge disintegration for enhancing full scale anaerobic digestion of municipal sludge. Batch disintegration tests and lab dewatering tests were also performed aiming at determining the release of organic compounds and assessing the impact of disintegration of excess sludge before the fermentation process of mixed sludge on the dewaterability of post-fermented sludge, respectively. In the study a disc disintegrator driven by a motor with a power of $30 \mathrm{~kW}$, revolutions $\mathrm{n}=2950 \mathrm{rpm}$ has been used. It was shown that with increase of energy consumed in the disintegration, the increased amounts of organic compounds were released from the sludge. It was also documented that the introduction of the excess sludge disintegration prior to fermentation tank, resulted in a significant increase in biogas production (by an average of $33.9 \%$ ) and in increase in volatile total solids reduction in the fermented sludge (by an average of $22.7 \%$ ). Moreover, the obtained results indicate the possibility of obtaining a higher degree of sludge dewatering, which was subjected to anaerobic stabilization with using disintegrated excess sludge.
\end{abstract}

\section{Introduction}

The legal requirements, more stringent in recent times in terms of quality of effluent discharged into the receivers (need for highly effective removal of nitrogen and phosphorus from wastewater), and in terms of how to deal with waste sludge appearing in the process of wastewater treatment (retreat from landfilling of sludge and the need to the use of other advanced processes that require complex technology including composting, drying or

* Corresponding author: katarzyna.szmeichel@pw.edu.pl 
incineration) have contributed to a significant increase in energy consumption in the processes of wastewater and sludge treatment, and thus increase the expenses of the operators. Published by Chamber of Commerce "Polish Waterworks" data [1] showed that in 2015 the specific energy consumption for technological processes in the Polish wastewater treatment plants (WWTP) were in the range of $0.12-2.60 \mathrm{kWh} / \mathrm{m}^{3}$ of the treated wastewater and it was significantly higher than specified for the year 2014 $\left(0.05-1.75 \mathrm{kWh} / \mathrm{m}^{3}\right)$. Thus, operators began searching for solutions that will allow for the gradual reduction of energy consumption and reducing expenses for its purchase. To decrease the costs of electricity, so-called renewable energy sources (RES) are increasingly used, including mainly biogas, but also wind energy, photovoltaic panels and heat pumps. The first of the above-mentioned RES is closely linked to the effectiveness of the process of anaerobic stabilization of waste sludge. Ensuring the appropriate parameters of the fermentation process and quality of the substrate introduced into anaerobic digester affects the amount of produced biogas as well as its calorific value [2]. Taking under consideration the value of index energy self-sufficiency for Polish WWTP (the ratio of electricity produced at the plant in cogeneration units to the annual electricity demand in the plant) set for 2015 which are equal to $56.7 \%$ and $36.6 \%$ respectively for medium-sized and large enterprises [1], it becomes important to increase biogas production to increase their share in energy used for the needs of WWTP. It may be done, among others, by co-digestion process, which results in increase of calorific value of substrates entering the anaerobic digester [3]. Another solution is to precede an anaerobic sludge stabilization by a process, which will increase the availability of substrate in the sludge for bacteria carrying out acidogenesis and methanogenesis. The disintegration of excess sludge is such a process. With the pretreatment, an acceleration of hydrolysis by the increase of dissolved components, improvement of biodegradability and sludge dewatering can be achieved [4]. Many different types of sludge disintegration like ultrasonic treatment [5], high pressure homogenization [6], hydrodynamic cavitation [7], Fenton process [8], acidic thermal treatment [9], microwave treatment [10] have been investigated in half-scale and lab scale for the purpose of anaerobic digestion intensification. All these studies have documented the ability to achieve higher production of biogas. For example, Rani et al. [10] using the microwave pretreatment observed $57 \%$ increase in biogas production. Boni et al. [5] as a result of ultrasonic disintegration noted $30 \%$ increase in biogas production, and Patil et al. [7] using hydrodynamic cavitation got $56 \%$ increase in this parameter.

So far, few work describes the results obtained in full scale, and existing indicate that it is not always possible to achieve the expected increase in biogas production. Neis et al.[11] and Rittmann et al. [12] reported $30 \%$ and $60 \%$ increase in biogas production. On the other hand, Zielewicz [13] reports that only in 3 out of 9 analyzed WWTP achieved a substantial effect of the ultrasonic disintegration on intensification of the fermentation process, and only in one case a significant, amounting to $40 \%$, increase of biogas production has been noted. Therefore, the research in full scale has been undertaken in order to evaluate the effects of mechanical sludge disintegration for enhancing anaerobic digestion of municipal wastewater sludge. Research in technical scale have been preceded by a preliminary stage, the aim of which was to evaluate the release of organic compounds due to mechanical disintegration of excess sludge.

In this study also lab tests have been performed on dewatering of post-fermented sludge subjected to anaerobic stabilization, respectively without and with using of disintegrated excess sludge. Their objective was to assess the potential impact of disintegration of excess sludge before the fermentation process of mixed sludge on the dewaterability of post-fermented sludge, changing the optimal dose of polyelectrolyte for its conditioning prior to dewatering and obtained dewatering efficiency. 


\section{Methods}

\subsection{Characteristics of the disintegration apparatus}

A full scale disc disintegrator was used in this study. It consists of three discs: two fixed (guide discs) and one rotating connected with a shaft driven by an electric motor (patent No. 211672). Working surfaces of discs have been shaped by the cutting on them constant-width radial channels and five circumferential channels. This configuration creates on discs' working surfaces systems of sectoral protrusions. After placing the rotating disc between guide discs, its sectoral protrusions are located in the circumferential channels of fixed discs. Between the side surfaces of protrusions of rotating disc and the walls of the channels of the fixed disc a gap of constant width is formed, acting as a hydraulic seal. A bipolar electric motor with a power of $30 \mathrm{~kW}$ and a nominal rotational speed of $2950 \mathrm{rpm}$ was used to drive the disintegrator. The motor is powered by a frequency converter capable of different speeds in the range $0-4000 \mathrm{rpm}$. Flow through the device is regulated in the range of 0 to $10 \mathrm{~m}^{3} / \mathrm{h}$. The flow system is equipped with a bypass.

\subsection{Disintegration batch tests}

The disintegration batch tests were carried out by repeated feeding the disc disintegrator with a 60-litre sample of thickened excess activated sludge (total solids (TS): $5.35 \pm 0.67 \%$ ). The device was operating at a sludge throughput of about $3.0 \mathrm{~m}^{3} / \mathrm{h}$. The process was carried out in a closed circle. After introducing a selected amount of energy, expressed as energy density $\left(\varepsilon_{\mathrm{L}}: 70,140,210\right.$ and $\left.280 \mathrm{~kJ} / \mathrm{L}\right)$, to the sludge under the disintegration process, a $0.5 \mathrm{~L}$ sample of disintegrated sludge was collected from a continuously stirred buffer tank. Immediately after this the liquid (subsequently called filtrate) was separated from the sludge in each sample. For this purpose the sludge was centrifuged for $30 \mathrm{~min}$ at $19621 \mathrm{~g}$ (centrifuge MPW-350) and then filtered with $0.45 \mu \mathrm{m}$ filters. The scope of the analysis included: 1) TS in raw sludge (samples not subjected to the disintegration process), 2) soluble chemical oxygen demand (SCOD) and volatile fatty acids (VFA) concentrations in filtrate before and after disintegration and 3) sludge disintegration degree (DD) according to Nickle and Neis [14]. In the experiment, seven repetition of the disintegration batch test were conducted in 3-weeks intervals. For each of them a new portion of sludge was delivered from a local WWTP.

\subsection{Evaluation of impact of thickened excess sludge disintegration on the efficiency of methane fermentation process}

The experiment aiming at evaluating the impact of mechanical disintegration of the thickened excess sludge on the efficiency of the process of anaerobic digestion was carried out for 8 months in a full scale at the WWTP of population equivalent equal to 107700 . It was assumed that the whole flow of the thickened excess sludge directed to the digester would be subjected to the process of disintegration, and energy density at which the process will be performed would be selected based on the results of batch disintegration tests (carried out in the initial stage of research). Excess sludge were fed to the disintegrator right from the mechanical thickener, and after disintegration process were directed back to the thickener, and from it to a mix sludge tank, wherein they were mixed with thickened primary sludge. Disintegrator worked for 16 hours a day (at what time excess sludge 
thickener was working), disintegrating $89 \mathrm{~m}^{3}$ thickened excess sludge. The mixed sludge in an amount of $118 \mathrm{~m}^{3} / \mathrm{d}$ was directed into the digester of working volume of $5000 \mathrm{~m}^{3}$. The process of anaerobic digestion was carried out at $34^{\circ} \mathrm{C}$, retention time $42.4 \mathrm{~d}$. During the experiment the TS of thickened excess sludge directed to the disintegration was $4.08+0.61 \%$, and the percentage share of VTS was $80.7+2.28 \%$. The values of these indicators characterizing the mixed sludge fed to a digester were respectively $4.95+0.31 \%$ and $84.6+3.11 \%$.

To evaluate the effect of mechanical disintegration of the thickened excess sludge on the efficiency of the process of anaerobic digestion, the concentration of TS and VTS was monitored in sludge introduced to and discharged from the digester. On this basis the reduction of VTS (expressed in $\mathrm{kg}$ VTS/d) was determined. Also the observations of the amount of the produced biogas were carried out. The results were compared with the effects of anaerobic digestion obtained before installing the disintegrator (average values of reduction of VTS and the amount of produced biogas from a period of 12 months prior to starting the disintegration have been obtained from the operator of the WWTP).

\subsection{Sludge dewatering tests}

Tests of dewatering were carried out by filtration on a Büchner funnel and by lab centrifuge, always with use of the pre-flocculated sludge by optimal dose of cationic polyelectrolyte Zetag 8180 (the same polyelectrolyte was used to support the dewatering of post-fermented sludge in industrial scale). The optimal dose of the polyelectrolyte was determined based on the smallest value of capillary suction time (CST). Dewatering on the Büchner funnel was conducted using a sludge sample of $100 \mathrm{~mL}$, a standard filter to determine the specific resistance of filtration (Whatman ${ }^{\circledR}$ quantitative filter paper, ashless, Grade 41) under a pressure of $0.05 \mathrm{MPa}$ and the filtration time 10 minutes. For dewatering using centrifugal force, a laboratory centrifuge type MPW-350 was used working with centrifugal acceleration $19621 \mathrm{~g}$, at constant spin time of 10 minutes. The dewatering efficiency was measured by determining in each case the TS concentration of the dewatered sludge.

NOTE: It should be emphasized that the concentration of TS in dewatered sludge in the above-specified laboratory conditions can never be compared directly with the values of TS in sludge dewatered using devices on a technical scale. However, they may serve as relative comparisons of changes in the ability of the sludge to release water; in the present case, depending on the fact of the use (or not) the process of disintegration of excess sludge before the fermentation process.

\subsection{Analytics}

All chemical analyses were performed in duplicates in accordance with APHA Standard Methods [15].

\section{Results and discussion}

\subsection{Effects of mechanical disintegration of excess activated sludge on organic compound release}

Mechanical disintegration was used to improve the bioavailability of sludge particulate material. As a result of disintegration, soluble organic compounds are released from the activated sludge flocs that can be readily used to produce methane during anaerobic 
digestion [16]. From the Table 1 it is evident that with the increase of energy consumed in the disintegration, the increased amounts of organic compounds (SCOD) were released from the sludge. Part of them was VFA. The phenomenon of obtaining VFA was called acidification. It can be seen that although the increase in energy density allowed getting the increase of SCOD concentration, the acidification was observed only to a certain level of energy density. The "inhibition" of acidification was observed at $210 \mathrm{~kJ} / \mathrm{L}$.

Table 1. The effect of energy density on SCOD and VFA release from sludge.

\begin{tabular}{|c|c|c|c|c|c|c|}
\hline \multirow{2}{*}{ Parameter } & \multirow{2}{*}{ Unit } & \multirow{2}{*}{$\begin{array}{c}\text { Before } \\
\text { disintegration }\end{array}$} & $70 \mathrm{~kJ} / \mathrm{L}$ & $140 \mathrm{~kJ} / \mathrm{L}$ & $210 \mathrm{~kJ} / \mathrm{L}$ & $280 \mathrm{~kJ} / \mathrm{L}$ \\
\cline { 3 - 7 } & \multirow{3}{*}{$\mathrm{SCOD}$} & $92-411$ & $1104-2375$ & $\begin{array}{c}2694- \\
6111\end{array}$ & $6152-9153$ & $7410-11451$ \\
\cline { 3 - 7 } & \multirow{2}{*}{$\mathrm{mgO} / \mathrm{L}$} & $160 \pm 114^{*}$ & $1784 \pm 506^{*}$ & $\begin{array}{c}4660 \pm 130 \\
9^{*}\end{array}$ & $\begin{array}{c}7659 \pm 104 \\
6^{*}\end{array}$ & $9520 \pm 1398^{*}$ \\
\cline { 3 - 7 } & \multirow{2}{*}{$\mathrm{VFA}$} & $3.0-28$ & $77-239$ & $361-868$ & $590-1000$ & $590-1000$ \\
\cline { 3 - 7 } & $\mathrm{mg} / \mathrm{L}$ & $11 \pm 8.1^{*}$ & $123 \pm 55^{*}$ & $623 \pm 196^{*}$ & $872 \pm 133^{*}$ & $886 \pm 139^{*}$ \\
\hline
\end{tabular}

*) average \pm standard deviations

Analyzing the relationship between VFA and SCOD depending on the energy density (Fig.1) it was found that the highest percentage of VFA in the organic compounds released form activated sludge flocs was achieved with a process of disintegration performed at energy density equal to $140 \mathrm{~kJ} / \mathrm{L}$. Analyzing relationships between ratio SCOD:VFA and the disintegration degree it could be noted that the minimum values of this ratio occurred when DD remained in the range of 9-17\%. Higher values SCOD:VFA achieved for $\mathrm{DD}<9 \%$ can be attributed to the fact that they were obtained in the initial stage of the disintegration $\left(\varepsilon_{\mathrm{L}}-70 \mathrm{~kJ} / \mathrm{L}\right)$. Most likely then the breakup of macrostructures of activated excess sludge occurred, resulting mainly in the release of long-chain organic compounds. The increase in ratio SCOD:VFA when DD exceeded the level of $17 \%$, resulted from a significant reduction in the efficiency of acidification, with continuous release of organic compounds other than VFA. It seems it might be affected by two factors: 1) at higher levels of disintegration observed mainly for $\varepsilon_{\mathrm{L}}=210 \mathrm{~kJ} / \mathrm{L}$ and $280 \mathrm{~kJ} / \mathrm{L}$ the amount of slowly biodegradable organic compounds originated from the lysis of bacterial cells increased, 2) with an increase in disintegration degree the structure of sludge floc changed significantly which no longer shaped dense clusters, but they formed "dispersed" mass of microorganisms and it could limit the propagation of the forces responsible for generating the VFA.

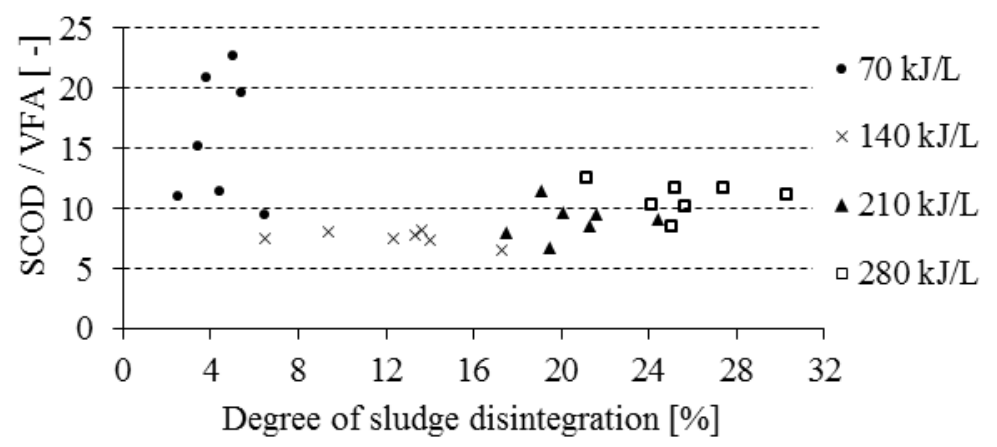

Fig. 1. SCOD:VFA as a function of the degree of sludge disintegration with consideration of energy density level. 


\subsection{Effects of mechanical disintegration of excess activated sludge on anaerobic digestion of municipal sludge}

Taking into account the results of disintegration batch tests, it was assumed that during the experiment the disintegrator will work with an energy density of $140 \mathrm{~kJ} / \mathrm{L}$. During installation at WWTP it turned out, however, that the subjecting the entire flow of excess sludge directed to the digester to disintegration with this energy density is not possible using the existing infrastructure in the plant. Therefore it was decided to carry out the experiment by disintegrating the entire flow of excess sludge, but at energy density resulting from the technical conditions at the plant, i.e. $20 \mathrm{~kJ} / \mathrm{L}$.

Before starting the experiment, the average values of VTS reduction and the biogas production were $2183 \mathrm{~kg} \mathrm{VTS} / \mathrm{d}$ and $2400 \mathrm{~m}^{3} / \mathrm{d}$ respectively (Tab. 2) and therefore a unit biogas production was at a level of $1.1 \mathrm{~m}^{3} / \mathrm{kg}$ VTS. The introduction of the disintegrated excess sludge prior to fermentation tank resulted in a significant increase in biogas production by an average of $33.9 \%$ (Tab.2). A similar percentage increase in the amount of biogas produced was observed by Neis et al. [11] (full-scale) and Boni et al. [5] (lab-scale) using ultrasonic pre-treatment. From the Figure 2 it is evident that in the initial phase of the experiment abrupt changes in the amount of produced biogas occurred, and after approx. 3.5 months since the start of disintegration the biogas production was relatively stable, remaining in the range of $3040-3421 \mathrm{~m}^{3} / \mathrm{d}$. The effect of application of excess sludge disintegration was also increase in VTS reduction in the fermented sludge by an average of $22.7 \%$. Unit biogas production for the analyzed period was $1.2 \mathrm{~m}^{3} / \mathrm{VTS} \mathrm{kg}$.

Table 2. Comparison of VTS reduction and biogas production for the periods before and after the mechanical disintegration of the thickened excess sludge.

\begin{tabular}{|c|c|c|c|}
\hline \multirow{2}{*}{ Parameter } & \multirow{2}{*}{ Unit } & \multicolumn{2}{|c|}{ Average values } \\
\cline { 3 - 4 } & & Period before disintegration & Period after disintegration \\
\hline VTS reduction & $\mathrm{kg} \mathrm{VTS} / \mathrm{d}$ & 2183 & 2678 \\
\hline Biogas production & $\mathrm{m}^{3} / \mathrm{d}$ & 2400 & 3213 \\
\hline Unit biogas production & $\mathrm{m}^{3} / \mathrm{kg}$ VTS & 1.10 & 1.20 \\
\hline
\end{tabular}



Fig. 2. Reduction of volatile total solids and biogas production on consecutive days of experiment.

Recorded significant increase in biogas production has to be understood in relation to the energy costs necessary to its inducing. Only the analysis of the size of the net increase in energy can give a full picture of rightfulness of the use of disintegration from the point of view of energy balance. We here are dealing with two types of energy. To drive the 
disintegrator, an energy is converted in the form of electricity, while biogas is a carrier of chemical energy. It is therefore impossible to make a direct comparison between them. Such a comparison is legitimate only if we make the conversion of one form of energy into another. Biogas as a carrier of chemical energy is a fuel of good quality and can be converted into electricity. A typical way to use biogas to produce electricity is its use in a piston engine or gas turbine. In WWTP much more popular form of biogas chemical energy conversion into electricity and heat is a piston engine. The process is carried out, obviously, with a certain efficiency far different from $100 \%$. For medium-sized gas engines with a nominal power of several hundred kilowatts an average electrical efficiency is about $40 \%$. In addition, the engine can produce functional heat in the form of hot water. It can be assumed that the amount of generated heat is equal to the amount of produced electricity. Assuming biogas calorific value is $23 \mathrm{MJ} / \mathrm{m}^{3}$, the surplus of produced biogas corresponds to the chemical energy of about $5200 \mathrm{kWh} / \mathrm{d}$. This amount of chemical energy allows producing approximately $2080 \mathrm{kWh} / \mathrm{d}$ of electricity and the same amount of heat. Electricity consumption by the disintegrator in the analyzed WWTP was significantly lower and equal to approximately $480 \mathrm{kWh}$. In case of installing in the present plant a piston engine powered by biogas, total energy benefits of using the disintegrator would amount to about $1600 \mathrm{kWh}$ of electricity and $7.5 \mathrm{GJ}(2080 \mathrm{kWh})$ of heat. The heat can be used to maintain the desired temperature in digester or to enhance the process of dewatered sludge drying.

During the experiment it was also observed that disintegration preceded the fermentation process had a positive effect on the rheological properties of fermented sludge which largely affected the work of the pumps feeding the sludge from digester to fermented sludge tank. A significant drawback of the technology, however, was the presence of foam in the digester. The cause of observed foaming was an increase in biogas production and problems with its discharge (too low flow capacity of an installation capturing biogas from digesters). In order to reduce the phenomenon described above there was necessary to increase the diameter of the biogas pipe. Modifications improved the working conditions of a digester.

\subsection{Effects of mechanical disintegration of excess activated sludge on sludge dewatering}

Table 3. The results of laboratory tests of dewatering post-fermented mixed sludge stabilized anaerobically without and with disintegrated excess sludge.

\begin{tabular}{|c|c|c|c|}
\hline \multicolumn{2}{|l|}{ Sample No. } & 1 & 2 \\
\hline \multicolumn{2}{|c|}{ Type of sludge fed to the digester } & $\begin{array}{l}\text { mixed (without } \\
\text { disintegration of } \\
\text { excess sludge) }\end{array}$ & $\begin{array}{c}\text { mixed (with } \\
\text { disintegration 100\% } \\
\text { of excess sludge) }\end{array}$ \\
\hline \multicolumn{2}{|c|}{$\begin{array}{c}\text { TS [\%] (in the post-fermented sample of sludge collected } \\
\text { from WWTP) }\end{array}$} & 2.38 & 3.06 \\
\hline \multicolumn{2}{|c|}{ CST of no-conditioned sludge $[\mathrm{s}]$} & 249 & 724 \\
\hline \multicolumn{2}{|c|}{ The optimal dose of polyelectrolyte Zetag 8180 [\% VTS] } & 0.86 & 0.44 \\
\hline \multicolumn{2}{|c|}{$\begin{array}{l}\text { CST of sludge conditioned with optimal dose of Zetag } \\
8180[\mathrm{~s}]\end{array}$} & 43.1 & 20.3 \\
\hline \multirow{2}{*}{$\begin{array}{c}\text { TS in sludge after dewatering [\%] } \\
\text { (sludge pre-conditioned with optimal } \\
\text { dose of polyelectrolyte) }\end{array}$} & Büchner funnel & 8.03 & 11.5 \\
\hline & Centrifuge & 7.62 & 10.0 \\
\hline
\end{tabular}


Laboratory dewatering tests were performed on 2 samples of fermented sludge delivered from WWTP. The results are shown in Table 3. The sample indicated by No. 1, of the concentration of TS: $2.38 \%$, is the sludge formed by the fermentation of the mixture of primary and the excess sludge which were not subjected to disintegration. The sample No. 2 (TS: $3.06 \%$ ) was the sludge formed in the fermentation of a mixture of primary and $100 \%$ of pre-disintegrated excess sludge, collected after replacing the entire volume of the digester (to ensure that in the entire volume of the digester was sludge together with sludge disintegrated involving excess sludge). The data shown in Table 3 indicate a significant reduction in the optimal dose of the polyelectrolyte for treated post-fermented sludge after anaerobic stabilization using entirely disintegrated excess sludge in relation to the fermented sludge without disintegration of the biological sludge even, that CST of the sludge prior to its conditioning was almost 3 times higher than the one of conventionally fermented sludge. The best indicator of growth of sludge dewaterability during mechanical dewatering is an increase in TS of dewatered sludge. In the analyzed samples of postfermented sludge a significant increase in this parameter for the sludge pre-flocculated with the optimal dose of polyelectrolyte was obtained for fermented sludge with use of disintegrated excess sludge (in sample 2, for sludge after filtration TS was $11.50 \%$, in relation to the sample $1-8.03 \%$ ), and after centrifuging $10 \%$ respectively, in relation to samples $1-7.62 \%$. The observed changes confirm the increase in the degree of dewatering of sludge fermented with disintegrated excess sludge and document the slightly larger effect of the process performed by pressure filtration.

\section{Conclusions}

The organic matter degradation and biogas production in the anaerobic sludge digestion were greatly improved by the mechanical disintegration of thickened excess sludge. The performed analyses regarding filtration properties of post-fermented sludge suggested the possibility of obtaining a higher degree of sludge dewatering, which was subjected to anaerobic stabilization with using disintegrated excess sludge (even at the lower dose of used polyelectrolyte) in relation to the sludge fermented without disintegration of excess sludge.

\section{References}

1. Benchmarking in Polish Water and Wastewater Sector in 2015 (in Polish)

2. G. Tchobanoglous, F.L. Burton, H.D. Stensel Wastewater Engineering: Treatment and Reuse (Metcalf \& Eddy Inc., McGraw-Hill, New York, USA, 2004)

3. K. Koch, M. Plabst, A. Schmidt, B. Helmreich, J.E. Drewes, Waste. Manage. 47, 28-33 (2016)

4. A.V. Ebenezer, S. Kaliappan, S.A. Kumar, I.T. Yeom, J.R. Banu, Bioresour. Technol. 185, 194-201 (2015)

5. M.R. Boni, E. D’Amato, A. Polettini, R. Pomi, A. Rossi, Waste. Manage. 48, 209-217 (2016)

6. W. Fang, P. Zhang, J. Ye, Y. Wu, H. Zhang, J. Liu, G. Zeng, Int. Biodeterior. Biodegradation 102, 126-130 (2015)

7. P.N. Patil, P.R. Gogate, L. Csoka, A. Dregelyi-Kiss, M. Horvath, Ultrason. Sonochem. 30, 79-86 (2016)

8. S. Kavitha, J.R. Banu, C.D. IvinShaju, S. Kaliappan, I.T. Yeom, Bioresour. Technol. 221, 1-8 (2016) 
9. M. Takashima, Y. Tanaka, J. Environ. Chem. Eng. 2, 2, 773-779 (2014)

10. R.U. Rani, S.A. Kumar, S. Kaliappan, I. Yeom, J.R. Banu, Waste. Manage. 33, 5, 1119-1127 (2013)

11. U. Neis, K. Nickle, A. Lunden, J. Environ. Sci. Health A 43, 13, 1541-1545 (2008)

12. B.E. Rittmann, H.S. Lee, H. Zhang, J. Alder, J.E. Banaszak, R. Lopez, Water Sci. Technol. 58, 10, 1895-1901 (2008)

13. E. Zielewicz, Gas, Water and Sanitary Engineering 90, 2, 69-76 (2016) (in Polish)

14. K. Nickle, U. Neis, Ultrason. Sonochem. 14, 450-455 (2007)

15. Standard Methods for the Examination of Water and Wastewater (20th edn. APHA, AWWA \& WEF, Washington, DC, USA, 1998)

16. F. Wang, Y. Wang, M. Ji, J. Hazard. Mater. 123, 145-150 (2005) 